\title{
Aberrant RON and MET Co-overexpression as Novel Prognostic Biomarkers of Shortened Patient Survival and Therapeutic Targets of Tyrosine Kinase Inhibitors in Pancreatic Cancer
}

OPEN ACCESS

Edited by:

Massimo Broggini,

Istituto Di Ricerche Farmacologiche

Mario Negri, Italy

Reviewed by:

Elisa Giovannetti,

VU University Medical

Center, Netherlands

Alex Cazes,

University of California, San Diego, United States

*Correspondence:

Hang-Ping Yao

yaohangping@zju.edu.cn

Ming-Hai Wang

minghai.wang@ttuhsc.edu

tThese authors have contributed equally to this work

Specialty section: This article was submitted to Cancer Molecular Targets and Therapeutics,

a section of the journal Frontiers in Oncology

Received: 02 August 2019 Accepted: 22 November 2019 Published: 05 December 2019

Citation:

Hu C-Y, Xu X-M, Hong B, Wu Z-G, Qian Y, Weng T-H, Liu Y-Z, Tang T-M, Wang $M-H$ and Yao H-P (2019)

Aberrant $R O N$ and MET

Co-overexpression as Novel Prognostic Biomarkers of Shortened

Patient Survival and Therapeutic Targets of Tyrosine Kinase Inhibitors in Pancreatic Cancer.

Front. Oncol. 9:1377. doi: 10.3389/fonc.2019.01377

\author{
Chen-Yu Hu ${ }^{1,2+}$, Xiang-Ming $\mathrm{Xu}^{3+}$, Bo Hong ${ }^{4}$, Zhi-Gang $\mathrm{Wu}^{1,2}$, Yun Qian ${ }^{5}$, \\ Tian-Hao Weng ${ }^{1,2}$, Yi-Zhi Liu ${ }^{1,2}$, Tao-Ming Tang ${ }^{1,2}$, Ming-Hai Wang ${ }^{1,2,6,7 *}$ and \\ Hang-Ping Yao ${ }^{1,2 *}$
}

${ }^{1}$ State Key Laboratory for Diagnosis \& Treatment of Infectious Diseases, The First Affiliated Hospital, Zhejiang University School of Medicine, Hangzhou, China, ${ }^{2}$ National Clinical Center for Diagnosis and Treatment of Infectious Disease, The First Affiliated Hospital, Zhejiang University School of Medicine, Hangzhou, China, ${ }^{3}$ Department of Colorectal Surgery, The First Affiliated Hospital, Zhejiang University School of Medicine, Hangzhou, China, ${ }^{4}$ Department of Pathology, The Second Affiliated Hospital, Hangzhou, China, ${ }^{5}$ Department of Clinical Laboratory, The Second Affiliated Hospital, Zhejiang University School of Medicine, Hangzhou, China, ${ }^{6}$ Cancer Biology Research Center, Amarillo, TX, United States,

${ }^{7}$ Department of Pharmaceutical Sciences, Texas Tech University Health Sciences Center School of Pharmacy, Amarillo, TX, United States

RON (recepteur d'origine nantais) and MET (hepatocyte growth factor receptor) are tyrosine kinase receptors. Various cancers have aberrant RON and MET expression and activation, which contribute to cancer cell proliferation, invasiveness, and metastasis. Here, we explored RON and MET expression in pancreatic cancer and their relationship with overall survival (OS) time, and evaluated their significance as therapeutic targets of tyrosine kinase inhibitors in pancreatic cancer. We enrolled 227 patients with pancreatic cancer in the study. RON and MET expression was analyzed by immunohistochemical staining. Four human pancreatic cancer cell lines expressing variable levels of RON or MET and four MET superfamily inhibitors (BMS777607, PHA665752, INCB28060, Tivantinib) were used. The effect of the four tyrosine kinase inhibitors on cell viability, migration, and apoptosis were determined using cell viability, scratch wound healing, and Caspase-Glo 3/7 assays. Cellular signaling was analyzed by immunoprecipitation and western blotting. The therapeutic efficacy of the tyrosine kinase inhibitors was determined with mouse xenograft pancreatic cancer models in vivo. There was wide aberrant RON and MET expression in the cancer tissues. In 227 pancreatic cancer samples, 33\% had RON overexpression, $41 \%$ had MET overexpression, and $15.4 \%$ had RON and MET co-overexpression. RON and MET expression were highly correlated. RON and MET expression levels were significantly related to OS. Patients with RON and MET co-overexpression had poorer OS. BMS777607 and PHA665752 inhibited pancreatic cancer cell viability and migration, and promoted apoptosis by inhibiting RON and MET phosphorylation and further inhibiting the downstream signaling pathways in vitro. They also inhibited tumor growth and further inhibited phosphorylated (phosphor)-RON and phospho-MET expression in the mouse xenograft models in vivo effectively. INCB28060, 
which inhibits the MET signaling pathway alone, was not effective. RON and MET can be important indicators of prognosis in pancreatic cancer. Tyrosine kinase inhibitors targeting $\mathrm{RON}$ and MET in pancreatic cancer are a novel and potential approach for pancreatic cancer therapy.

Keywords: pancreatic cancer, tyrosine kinase inhibitors, RON receptor tyrosine kinase, MET receptor tyrosine kinase, prognosis biomarker, therapeutic target

\section{INTRODUCTION}

Cancer currently poses a serious threat to human health. Advances in precision medicine have allowed many common cancers to be detected early and treated effectively, reducing mortality. As a leading cancer, pancreatic cancer has very high mortality. The 1 -year survival rate of pancreatic cancer is $<20 \%$. Due to the lack of early diagnosis and effective treatment, the death rate from pancreatic cancer will become the second leading cause of cancer-related death in the next 20 years (1-3). Therefore, there is an urgent need to explore more therapeutic targets.

RON (macrophage-stimulating 1 receptor, MST1R) is a member of the MET proto-oncogene family, which also includes another member, MET (MET proto-oncogene, receptor tyrosine kinase) $(4,5)$. MET and RON were discovered in the early 1980 s and early 1990 s, respectively $(4,6,7)$. The receptor tyrosine kinase (RTK) RON (7) and MET [also known as hepatocyte growth factor receptor [HGFR]; scatter factor (8)] are first produced as a single-chain $\sim 180$ $\mathrm{kDa}$ precursor, and then proteolytically cleaved to form a mature protein with two subunits: a $\sim 40-\mathrm{kDa}$ extracellular $\alpha$-subunit with the Sema domain responsible for ligand binding, receptor dimerization, and phosphorylation; and a $\sim 150$-kDa transmembrane $\beta$-subunit with intrinsic tyrosine kinase activity, linked by a disulfide bond (7, 9). MSP [macrophage-stimulating protein, also known as MST1 and hepatocyte growth factor-like [HGFL]] is a RON ligand, and HGF is a MET ligand. Many studies on mouse cell models have shown that RON and MET play an important role in normal embryonic development and organogenesis, but their functions are restricted in adults (10-12). There is aberrant RON and MET expression and activation in various cancers, including gastric, prostate, ovarian, and breast cancer,

\footnotetext{
Abbreviations: ADC Zt/g4-DM1, Monoclonal antibody (mAb) Zt/g4-drug maytansinoid conjugates; ATCC, American type culture collection; CI, Confidence interval; ELISA, Enzyme-linked immunosorbent assay; EMT, Epithelial to mesenchymal transition; ERK, Extracellular signal-regulated kinases; EGFR, Epidermal growth factor receptor; FBS, Fetal bovine serum; FITC, Fluorescein isothiocyanate; FTI, Farnesyltransferase inhibitor; HGF, Hepatocyte growth factor; IC50, Half maximal inhibitory concentration; IHC, Immunohistochemical; MAP, Mitogen-activated protein; MET, Hepatocyte growth factor receptor; MFI, Median fluorescence level; MST1R, Macrophage stimulating 1 receptor; mAb, Monoclonal antibody; MSP, Macrophage-stimulating protein; OS, Overall survival; PBS, Phosphate-buffered saline; PI-3K, Phosphatidylinositol 3-kinases; RON, Recepteur d'origine nantais; RTK, Receptor tyrosine kinase; RR, Relative risk; RLU, Relative light unit; TKI, Tyrosine kinase inhibitors; VEGF, Vascular endothelial growth factor.
}

and such aberrations contribute to cancer cell proliferation, invasiveness and metastasis $(7,13-15)$. Moreover, it has been experimentally confirmed that ligand-induced RON activation can transphosphorylate MET, and vice versa. Although the RON and MET ligands are different, they cross-talk and act synergistically in intracellular signaling $(9,16)$. The role of RON and MET in pancreatic cancer malignant progression, angiogenesis, and chemoresistance has also been studied extensively via genetic, biochemical, and biological models (1721). In the present study, we mainly focused on the coexpression characteristics and pathological significance of RON and MET in pancreatic cancer tissues. At the same time, many tyrosine kinase inhibitors (TKIs) and targeted drugs that inhibit RON or MET are also being developed (22-25). However, few studies have compared the inhibitory effects of different TKIs targeting RON or MET in pancreatic cancer. Therefore, whether RON and MET can be used as important prognostic indicators and new therapeutic targets in pancreatic cancer is worth further exploration.

Here, we used a panel of pancreatic cancer cell lines expressing different levels of RON and MET as the model. The cell lines have previously been used to determine the role of RON and MET in regulating pancreatic cancer tumorigenic activity (22). Here, we used four MET superfamily TKIs to explore their therapeutic effects on pancreatic cancer: BMS777607, PHA665752, INCB28060 (capmatinib; INC280), and Tivantinib (ARQ 197). BMS777607 is a selective adenosine triphosphate (ATP)-competitive TKI with high specificity for RON at a median inhibitory concentration (IC50) of $1.8 \mathrm{nM}$, and targets MET with an IC50 of $3.9 \mathrm{nM}$ (26). PHA665752 is a potent, selective, and ATP-competitive TKI of RON (IC50 $68 \mathrm{nM}$ ) and MET (IC50 $9 \mathrm{nM}$ ) (27). INCB28060 is a potent and selective TKI with high specificity for MET (IC50 $0.13 \mathrm{nM}$ ) (28). Tivantinib (ARQ 197), a novel and highly selective non-ATP-competitive MET inhibitor, can inhibit human recombinant MET with a calculated inhibitory constant (Ki) of $\sim 355 \mathrm{nM}$, and is currently in phase III cancer clinical trials $(29,30)$. Tivantinib (ARQ 197) exhibits anti-tumor activity independent of MET inhibition (31). Tivantinib can affect microtubule dynamics, induce G2/M arrest, and promote apoptosis $(32,33)$. As Tivantinib is the first MET-selective inhibitor to be used in advanced human clinical trials, we used it as a control inhibitor in the present study.

We explored RON and MET expression in pancreatic cancer and their relationship with survival time to investigate whether they can be used as a new prognostic marker in pancreatic cancer. Then, we explored the signaling pathways of aberrant 
RON and MET expression in pancreatic cancer, and evaluated the significance of RON and MET as therapeutic targets of TKIs targeting RON and/or MET in pancreatic cancer, further providing new means and therapy for treating pancreatic cancer in the future.

\section{MATERIALS AND METHODS \\ Cell Lines and Reagents}

Human pancreatic cancer cell lines expressing variable levels of RON and MET were selected as the TKI targeting model. The BxPC3 [KRAS proto-oncogene, GTPase wild-type [KRAS wt]], AsPC1 [KRAS [mutant, mut]], and Pancl [KRAS [mut]] cell lines were from American Type Cell Culture (ATCC, Manassas, VA, USA) and had been authenticated in 2010 with cytogenesis. The L3.6p1 cell line was provided by G.E. Gallick (University of Texas MD Anderson Cancer Center, Houston, TX, USA) (34). Flow cytometric and western blot analysis showed that the BxPC3 and AsPC1 cells had RON and MET co-expression. L3.6p1 cells express RON alone and Panc1 cells express MET alone (Figure S1). The cell lines were cultured in their appropriate culture medium supplemented with $10 \%$ fetal bovine serum. Anti-RON monoclonal antibodies $(\mathrm{mAbs}, \mathrm{Zt} / \mathrm{g} 4, \mathrm{Zt} / \mathrm{f} 2)$ and rabbit polyclonal immunoglobulin $\mathrm{G}$ (IgG) antibody R5029, specific to the RON C-terminus, were used as previously described $(23,25,35,36)$. Phosphorylated (phospho)-tyrosine mouse mAb (P-Tyr-100, Cat\# 9411) and rabbit antibodies to extracellular signal-regulated kinase $1 / 2$ (ERK1/2) (Cat\# 4695), AKT (Cat\# 4685), phospho-ERK1/2 (p44/42) (Cat\# 4376), and phospho-AKT (Cat\# 4060) were from Cell Signaling Technology (Beverly, MA, USA). METspecific rabbit IgG antibodies (Cat\# ab51067) were from Abcam (Burlingame, CA, USA). BMS777607, PHA665752, INCB28060, and Tivantinib were from MedChem Express (Monmouth Junction, NJ, USA) and stored at a concentration of $10 \mathrm{mM}$ in dimethyl sulfoxide (DMSO). Recombinant human MSP (Cat\# 352-MS), recombinant human HGF (Cat\# 294-HG), and the DuoSet IC human phospho-RON ELISA (enzyme-linked immunosorbent assay, cat. no. DYC1947-5) kit were from R\&D Systems (Minneapolis, MN, USA).

\section{Patients and Tissue Specimens}

We analyzed 227 patients who had been pathologically diagnosed with pancreatic cancer with or without liver metastases between January 2010 and June 2015 at the Affiliated Hospital, Zhejiang University School of Medicine. All patients underwent pathological biopsy for pancreatic cancer surgery. The clinical parameters included patient demographics, tumornode-metastasis (TNM) stage, tumor differentiation, tumor size, and treatment modality. Furthermore, 20 patients with benign pancreatic or liver disease, such as pancreatitis and cysts, and hepatolithiasis, were enrolled as a control group. All tissues were fixed in $10 \%$ buffered formalin and embedded in paraffin. This study was approved by the Ethics Committee of the First Affiliated Hospital (reference numbers: 2017427-1), Zhejiang University School of Medicine.

\section{IHC Staining and Evaluation of RON and MET in Pancreatic Cancer Tissue}

In human pancreatic cancer tissue, IHC staining was carried out using $\mathrm{Zt} / \mathrm{f} 2(5 \mu \mathrm{g} / \mathrm{mL})$ as the primary antibody for RON and rabbit anti-MET mAb (1:100, 51,067, abcam) for MET, followed by EnVision System reagents (Dako, Carpentaria, CA, USA) as previously described (35). The negative control was performed by replacing the primary antibody with isotype-matched mouse IgG $(5 \mu \mathrm{g} / \mathrm{mL})$ (Figure S3). Human normal/benign pancreas tissue were used as the negative control. Two pathologists without knowledge of the patients' clinical records examined and scored the sections. Five tumor fields under $\times 400$ magnification were randomly selected. Cytoplasmic and/or tumor cell membrane staining were considered to indicate positive expression. RON and MET expression were determined using a semiquantitative system as previously described (35). The proportion of positive cells was scored as follows: $0(<5 \%), 1(6-25 \%), 2(26-50 \%)$, 3 (51-75\%), and 4 (>75\%). The staining level was evaluated as follows: 0 (no staining), 1 (weak staining, light yellow), 2 (moderate staining, yellowish brown), and 3 (strong staining, brown). The sum score, determined by adding up the positive proportion score and the staining level score, was as follows: 0 (negative; $0+$ ), 1-3 (weakly positive; $1+$ ), 4-5 (moderately positive; $2+$ ), and 6-7 (strongly positive; $3+$ ).

\section{Cell Viability and Caspase-Glo $3 / 7$ Assays}

Pancreatic cancer cells $\left(1 \times 10^{4}\right.$ cells per well in a 96-well plate in triplicate) were incubated in a $5 \% \mathrm{CO}_{2}$ atmosphere at $37^{\circ} \mathrm{C}$. Cell viability at 24,48 , and $72 \mathrm{~h}$ after TKI treatment $(0-$ $15 \mu \mathrm{M}$ ) was determined using Cell Counting Kit-8 (CCK-8, 10 $\mu \mathrm{L} /$ well, cat. no. HY-K0301-100T; MedChem Express). BxPC3 cell apoptosis following TKI treatment $(0-10 \mu \mathrm{M})$ was measured using an ApoLive-Glo Multiplex Assay kit (size: $5 \times 10 \mathrm{~mL}$, cat. no. \#G6411; Promega, Madison, WI, USA) to detect caspase-3/7 activity in the cells according to the manufacturer's instructions.

\section{Cell Migration Assays}

The effect of the TKIs on pancreatic cancer cell migration was detected using a wound healing assay. Pancreatic cancer cells $\left(5 \times 10^{5}\right.$ cells $)$ were seeded in 6-well plates and allowed to grow until $100 \%$ confluent. A scratch was made in the plate using a P200 pipette tip after the inhibitors (1.5 $\mu \mathrm{M}$ BMS777607, $5 \mu$ M INCB28060, $1.5 \mu$ M PHA665752, $0.15 \mu$ M Tivantinib) had been added. According to the CCK-8 experimental results at $24 \mathrm{~h}$ (Figure S2), the cell viability rate under the above drug concentration was $>80 \%$. Images were collected at 0 and $24 \mathrm{~h}$ under an inverted microscope (Ziess, Oberkochen, Germany). Cell migration was analyzed using National Institutes of Health (NIH, Bethesda, MD, USA) ImageJ software and GraphPad 7 (GraphPad Software, San Diego, USA).

\section{Phosphorylation, Immunoprecipitation, and Western Blotting}

These steps were conducted as previously described $(23,25)$. The phosphorylation assay was performed by stimulating $\mathrm{BxPC} 3$ cells $\left(2 \times 10^{6}\right.$ cells $\left./ \mathrm{mL} / \mathrm{sample}\right)$ with $2 \mathrm{nM}$ MSP (RON activation) and $2 \mathrm{nM}$ HGF (MET activation), followed by TKIs $(5 \mu \mathrm{M}$ 
BMS777607, $5 \mu \mathrm{M}$ INCB28060, $5 \mu \mathrm{M}$ PHA665752, $0.5 \mu \mathrm{M}$ Tivantinib) at $37^{\circ} \mathrm{C}$ for $60 \mathrm{~min}$ (25). Cellular proteins from cell lysates (30 $\mu \mathrm{g}$ per sample) and tissue lysates (50 $\mu \mathrm{g}$ per sample) were separated in $8 \%$ sodium dodecyl sulfate-polyacrylamide gel electrophoresis (SDS-PAGE) under reduced conditions. RON, MET, or other signaling proteins were detected by western blotting using R5029, ab51067, or the corresponding antibodies, visualized using enhanced chemiluminescence reagents and were analyzed using the VersaDoc MP 5000 Imaging system (Bio$\mathrm{Rad})$. The membranes also were reprobed with antibodies to GAPDH (glyceraldehyde-3-phosphate dehydrogenase) to ensure equal sample loading.

For immunoprecipitation, cellular proteins (250 $\mu \mathrm{g}$ per sample) were mixed with anti-phospho-tyrosine PY-100 (1:100) coupled to protein G Sepharose beads. Proteins were separated in $8 \%$ SDS-PAGE under reduced conditions. Phospho-RON or phospho-MET was detected by western blotting using R5029 or ab51067.

\section{Human Phospho-RON ELISA}

The DuoSet IC ELISA was used for measuring human phosphoRON in cell lysates according to the manufacturer's instructions. Capture antibody (mouse anti-human RON, $8.0 \mu \mathrm{g} / \mathrm{mL}$ in phosphate-buffered saline [PBS]) was coated in a 96-well microplate and incubated overnight at room temperature. Then, cell lysates $(30 \mu \mathrm{g} / 100 \mu \mathrm{L} /$ well $)$ were added and incubated for $2 \mathrm{~h}$ at room temperature, followed by the addition of diluted antiphospho-tyrosine PY-100-horseradish peroxidase (HRP) to each well. After adding substrate solution, the absorbance of each well was measured using a microplate reader (Bio-Tek ELx800) at $450 \mathrm{~nm}$ wavelength. The phospho-RON levels in the cell lysates were evaluated based on the optical density value.

\section{Pancreatic Cancer Xenograft Model and TKI Treatment}

All mouse experiments were approved by the institutional animal care committee (reference numbers: 2017400-1). Female athymic nude mice ( 6 weeks old, Taconic, Cranbury, NJ) were acclimated to the animal housing facility for at least 1 week before the study. Then, the mice were injected with $5 \times 10^{6}$ BxPC3, AsPC1, L3.6p1, or Panc1 cells in the subcutaneous space of the right flank as previously described $(37,38)$. The mice were randomized to different groups ( $n=4$ per group). Treatment began when all tumors had a mean volume of $\sim 100$ $\mathrm{mm}^{3}$. BMS777607, INCB28060, PHA665752, or Tivantinib was administered by gavage at $25,5,25$, and $20 \mathrm{mg} / \mathrm{kg}$ daily per mouse, respectively, and continued for 14 days. Control mice were injected with vehicle (DMSO in PBS). Tumor volume and mouse body weights were recorded every 4 days. The volume (V) of the subcutaneous tumors was calculated as follows: $\mathrm{V}=$ $\left(\right.$ length $\times$ width $\left.^{2}\right) / 2$. The animals were euthanized if the tumors became necrotic or ulcerated through the skin or when tumor volumes were $>2,000 \mathrm{~mm}^{3}$ or if the mice bred for $>60$ days after becoming tumor-burdened. The tumors were harvested for the subsequent experiments.

\section{Data Analysis and Statistical Significance}

Statistical analysis was performed using SPSS (v17.0; IBM Corporation, Armonk, NY, USA) and GraphPad 7. The relationship between RON and MET expression and clinicopathological characteristics was compared using the chi-square test. Overall survival (OS) was calculated from the diagnosis of pancreatic cancer until death or the date of the last follow-up. Survival data were analyzed by the Kaplan-Meier method and log rank test. The independent prognostic factors of survival were identified using Cox proportional hazard model analysis. The significance of the experimental and control groups was analyzed using one-way analysis of variance (ANOVA) or the two independent samples $t$-test. Results are shown as the mean \pm SD. $P<0.05$ was considered statistically significant.

\section{RESULTS}

\section{RON and MET Expression in Pancreatic Cancer and Their Relationship With Clinicopathological Characteristics}

A total of 227 patients (156 men and 71 women) with pancreatic cancer were enrolled in the study. All patients were followed up until December 2018, when only 10 patients were confirmed to be still alive. The median age at tumorectomy was 63 years (range, 26-93 years). All patients were diagnosed with infiltrating ductal adenocarcinoma. Table 1 summarizes the characteristics of the patient population.

RON and MET staining was detected in the cell membrane and cytoplasm in cancerous and non-cancerous cells in patients with pancreatic cancer (Figures 1A,B). The pancreatic cancer samples had significantly higher proportions of positive RON expression (195 of 227 patients, 85.9\%) and MET expression (207 of 227 patients, $91.2 \%$ ) compared with the normal/benign pancreatic tissue samples ( 5 of 20 patients, 25\%). Moreover, the positive samples in the normal/benign pancreatic tissues all had weak expression. Of the 227 pancreatic cancer samples, $33 \%$ had RON overexpression (3+), 41\% had MET overexpression (3+), and $15.4 \%$ had RON and MET co-overexpression. Compared to RON, MET was more widely overexpressed in pancreatic cancer tissues. Table 1 shows the relationship between RON and MET expression and the clinicopathological characteristics. Elevated RON and MET expression was associated with distant metastasis $(p<0.05)$ and tumor size $(p<0.05)$, respectively. RON expression level was highly correlated with MET expression ( $p$ $<0.01)$. However, RON and MET expression was not associated with patient age at tumorectomy ( $<65$ vs. $\geq 65$ years), gender, lymph node metastasis, tumor-node-metastasis (TNM) stage, or chemotherapy treatment.

\section{Relationship Between RON and MET Expression and OS}

The role of RON and MET expression in OS was assessed using Kaplan-Meier analysis and the log-rank test (Table 2). At the final follow-up, the median OS of the 227 samples was $15.0 \pm$ 0.77 months [95\% confidence interval [CI], 13.48-16.52 months]. RON and MET expression levels were significantly related to 
TABLE 1 | Correlation between RON/MET expression and clinical characteristics of patients with pancreatic cancer.

\begin{tabular}{|c|c|c|c|c|c|c|c|c|c|}
\hline \multirow[t]{2}{*}{ Characteristic } & \multirow[t]{2}{*}{ Cases } & \multicolumn{3}{|c|}{ RON expression $(P)$} & \multirow[t]{2}{*}{$P$-value } & \multicolumn{3}{|c|}{ MET expression $(P)$} & \multirow[t]{2}{*}{$P$-value } \\
\hline & & Overexpressed & Weak/moderate & Negative & & Overexpressed & Weak/moderate & Negative & \\
\hline Age (years) & & & $\left(\chi^{2}=0.562, P>0.05\right)$ & & 0.755 & & $\left(x^{2}=1.562, P>0.05\right)$ & & 0.458 \\
\hline$<63$ & $111(48.9 \%)$ & $38(34.2 \%)$ & 56 (50.5\%) & $17(15.3 \%)$ & & $42(37.8 \%)$ & 57 (51.4\%) & $12(10.8 \%)$ & \\
\hline$\geq 63$ & $116(51.1 \%)$ & 37 (31.9\%) & 64 (55.2\%) & $15(12.9 \%)$ & & $51(44.0 \%)$ & 57 (49.1\%) & $8(6.9 \%)$ & \\
\hline Sex & & & $\left(\chi^{2}=1.718, P>0.05\right)$ & & 0.424 & & $\left(\chi^{2}=0.074, P>0.05\right)$ & & 0.963 \\
\hline Male & $156(68.7 \%)$ & 48 (30.8\%) & 87 (55.8\%) & $21(13.5 \%)$ & & $63(40.4 \%)$ & 79 (50.6\%) & $14(9.0 \%)$ & \\
\hline Female & $71(31.3 \%)$ & $27(30.8 \%)$ & $33(46.5 \%)$ & $11(15.5 \%)$ & & $30(42.3 \%)$ & 35 (49.3\%) & $6(8.5 \%)$ & \\
\hline Tumor size & & & $\left(\chi^{2}=2.617, P>0.05\right)$ & & 0.270 & & $\left(\chi^{2}=7.304, P<0.05\right)$ & & 0.026 \\
\hline $1 \sim 2$ & $71(31.3 \%)$ & 19 (26.8\%) & $39(54.9 \%)$ & $13(18.3 \%)$ & & $21(29.6 \%)$ & $40(56.3 \%)$ & $10(14.1 \%)$ & \\
\hline $3 \sim 4$ & 156 (68.7\%) & 56 (35.9\%) & $81(51.9 \%)$ & $19(12.2 \%)$ & & 72 (46.2\%) & 74 (47.4\%) & $10(6.4 \%)$ & \\
\hline Lymph node metastasis & & & $\left(\chi^{2}=1.730, P>0.05\right)$ & & 0.421 & & $\left(\chi^{2}=0.005, P>0.05\right)$ & & 0.997 \\
\hline Yes & $103(45.4 \%)$ & $30(29.1 \%)$ & 56 (54.4\%) & $17(16.5 \%)$ & & $42(40.8 \%)$ & 52 (50.5\%) & $9(8.7 \%)$ & \\
\hline None & $124(54.6 \%)$ & 45 (36.3\%) & 64 (51.6\%) & $15(12.1 \%)$ & & $51(41.1 \%)$ & $62(50.0 \%)$ & $11(8.9 \%)$ & \\
\hline Distant metastasis & & & $\left(\chi^{2}=7.938, P<0.05\right)$ & & 0.019 & & $\left(x^{2}=4.873, P>0.05\right)$ & & 0.087 \\
\hline Yes & $59(26.0 \%)$ & $28(47.5 \%)$ & $23(39.0 \%)$ & $8(13.6 \%)$ & & $30(50.8 \%)$ & 27 (45.8\%) & $2(3.4 \%)$ & \\
\hline None & 168 (74.0\%) & 47 (28.0\%) & 97 (57.7\%) & $24(14.3 \%)$ & & 63 (37.5\%) & 87 (51.8\%) & 18 (10.7\%) & \\
\hline TNM stage & & & $\left(\chi^{2}=3.051, P>0.05\right)$ & & 0.217 & & $\left(\chi^{2}=4.163, P>0.05\right)$ & & 0.125 \\
\hline $1 \sim 2$ & $150(66.0 \%)$ & $44(29.3 \%)$ & 85 (56.7\%) & $21(14.0 \%)$ & & $57(38.0 \%)$ & 76 (50.7\%) & 17 (11.3\%) & \\
\hline $3 \sim 4$ & 77 (34.0\%) & $31(40.3 \%)$ & $35(45.5 \%)$ & $11(14.3 \%)$ & & $36(46.8 \%)$ & 38 (49.4\%) & $3(3.9 \%)$ & \\
\hline Differentiation & & & $\left(\chi^{2}=7.983, P>0.05\right)$ & & 0.092 & & $\left(\chi^{2}=1.341, P>0.05\right)$ & & 0.854 \\
\hline Well & 25 (11.0\%) & $8(32.0 \%)$ & $15(60.0 \%)$ & $2(8.0 \%)$ & & $11(44.0 \%)$ & $13(52.0 \%)$ & $1(4.0 \%)$ & \\
\hline Moderate & $170(74.9 \%)$ & $50(29.4 \%)$ & $94(55.3 \%)$ & $26(15.3 \%)$ & & $68(40.0 \%)$ & 85 (50.0\%) & $17(10.0 \%)$ & \\
\hline Poor & $32(14.1 \%)$ & $17(53.1 \%)$ & $11(34.4 \%)$ & $4(12.5 \%)$ & & $14(43.8 \%)$ & $16(50.0 \%)$ & 2 (6.3\%) & \\
\hline Treatment & & & $\left(\chi^{2}=4.886, P>0.05\right)$ & & 0.087 & & $\left(\chi^{2}=2.836, P>0.05\right)$ & & 0.242 \\
\hline Chemotherapy & 95 (41.9\%) & 31 (32.6\%) & 56 (58.9\%) & $8(8.4 \%)$ & & 45 (47.4\%) & 42 (44.2\%) & $8(8.4 \%)$ & \\
\hline None & $132(58.1 \%)$ & 44 (33.3\%) & $64(48.5 \%)$ & $24(18.2 \%)$ & & 48 (36.4\%) & 72 (54.5\%) & $12(9.1 \%)$ & \\
\hline MET expression & & & $\left(\chi^{2}=14.303, P<0.05\right)$ & & 0.006 & & & & \\
\hline Overexpressed & $93(41.0 \%)$ & 35 (37.6\%) & $53(57.0 \%)$ & $5(5.4 \%)$ & & & & & \\
\hline Weak/moderate & 114 (50.2\%) & 35 (30.7\%) & $59(51.8 \%)$ & $20(17.5 \%)$ & & & & & \\
\hline Negative & $20(8.8 \%)$ & $5(25.0 \%)$ & $8(40.0 \%)$ & 7 (35.0\%) & & & & & \\
\hline
\end{tabular}

Bold values means statistically significant. 

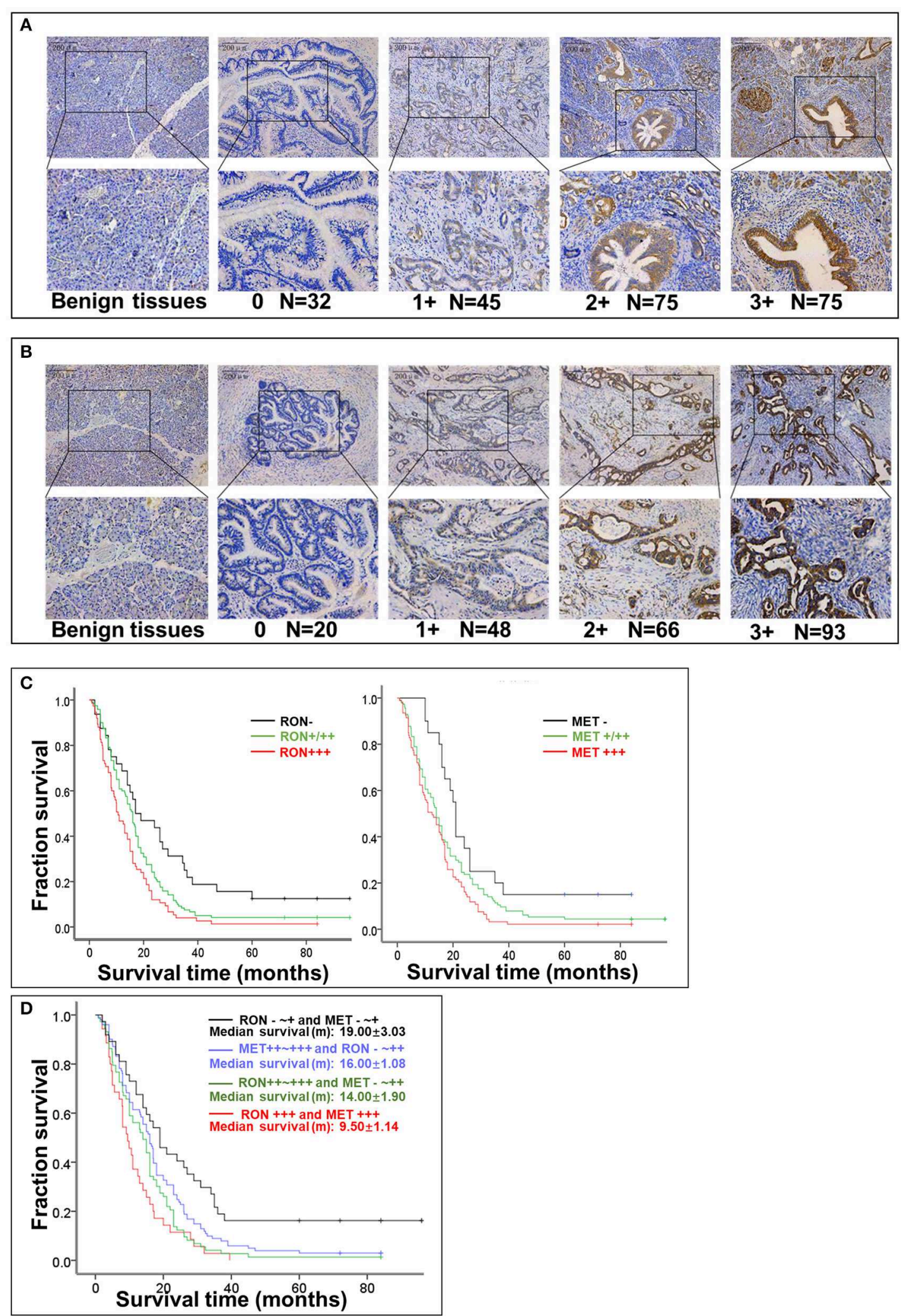

FIGURE 1 | Relationship between RON and MET expression levels in pancreatic cancer tissue samples and OS. (A) RON expression level in benign tissues and pancreatic cancer tissues. Original magnification ×100 (all photomicrographs). (B) MET expression level in benign tissues and pancreatic cancer tissue. (C) Kaplan-Meier plots with log-rank test analysis of the relationship between RON or MET expression level and survival. (D) Relationship between RON and MET co-expression and survival. 
TABLE 2 | Univariate analysis of overall survival.

\begin{tabular}{|c|c|c|c|c|}
\hline Characteristic & Cases & Median survival (months) & 95\% Cl (months) & $P$-value \\
\hline \multicolumn{5}{|l|}{ Age (years) } \\
\hline$<63$ & 111 & $16.000 \pm 1.109$ & 13.827-18.173 & 0.002 \\
\hline$\geq 63$ & 116 & $11.000 \pm 1.498$ & $8.064-13.936$ & \\
\hline \multicolumn{5}{|l|}{ Sex } \\
\hline Male & 156 & $15.500 \pm 0.812$ & 13.909-17.091 & 0.565 \\
\hline Female & 71 & $12.500 \pm 1.302$ & $9.948-15.052$ & \\
\hline \multicolumn{5}{|l|}{ Tumor size } \\
\hline $1 \sim 2$ & 71 & $20.000 \pm 1.149$ & $17.748-22.252$ & 0.000 \\
\hline $3 \sim 4$ & 156 & $10.000 \pm 1.171$ & $7.705-12.295$ & \\
\hline \multicolumn{5}{|c|}{ Lymph node metastasis } \\
\hline Yes & 103 & $11.000 \pm 1.267$ & $8.516-13.484$ & 0.010 \\
\hline None & 124 & $16.000 \pm 0.879$ & $14.277-17.723$ & \\
\hline \multicolumn{5}{|l|}{ Distant metastasis } \\
\hline Yes & 59 & $7.000 \pm 0.524$ & $5.972-8.028$ & 0.000 \\
\hline None & 168 & $17.000 \pm 0.647$ & $15.731-18.269$ & \\
\hline \multicolumn{5}{|l|}{ TNM stage } \\
\hline $1 \sim 2$ & 150 & $17.000 \pm 0.612$ & 15.801-18.199 & 0.000 \\
\hline $3 \sim 4$ & 77 & $7.900 \pm 0.797$ & $6.338-9.462$ & \\
\hline \multicolumn{5}{|l|}{ Differentiation } \\
\hline Well & 25 & $16.500 \pm 2.998$ & $10.625-22.375$ & 0.216 \\
\hline Moderate & 170 & $15.000 \pm 0.848$ & 13.338-16.662 & \\
\hline Poor & 32 & $9.900 \pm 2.828$ & 4.356-15.444 & \\
\hline \multicolumn{5}{|l|}{ Treatment } \\
\hline Chemotherapy & 95 & $17.100 \pm 0.677$ & $15.774-18.426$ & 0.035 \\
\hline None & 132 & $11.000 \pm 1.092$ & $8.859-13.141$ & \\
\hline \multicolumn{5}{|l|}{ RON expression } \\
\hline Overexpressed & 75 & $10.600 \pm 1.378$ & $7.900-13.300$ & 0.001 \\
\hline Weak/moderate & 120 & $16.000 \pm 1.128$ & 13.789-18.211 & \\
\hline Negative & 32 & $17.000 \pm 5.657$ & 5.913-28.087 & \\
\hline \multicolumn{5}{|l|}{ MET expression } \\
\hline Overexpressed & 93 & $12.500 \pm 1.854$ & $8.865-16.135$ & 0.006 \\
\hline Weak/moderate & 114 & $14.000 \pm 1.143$ & $11.759-16.241$ & \\
\hline Negative & 20 & $21.000 \pm 0.730$ & $19.569-22.431$ & \\
\hline
\end{tabular}

OS $(p<0.01)$. Patients with RON overexpression had poorer OS compared with patients with weak/moderate or negative RON expression $(p<0.01)$ (Figure 1C). The correlation between MET expression and OS was similar to that of RON $(p<0.01)$ (Figure 1C). Patients with RON and MET co-overexpression (median survival: $9.50 \pm 1.14$ months) had significantly shorter survival than patients with RON or MET weak and negative expression (median survival: $19.00 \pm 3.03$ months $)(p<0.01)$ (Figure 1D). As novel tumor biomarkers, RON and MET as combined indicators of prognosis for predicting patient survival may have more clinical evaluation value than RON or MET alone. The other prognostic factors associated with decreased OS were age $(p<0.01)$, tumor size $(p<0.01)$, lymph node metastasis $(p$ $<0.05)$, distant metastasis $(p<0.01)$, TNM stage $(p<0.01)$, and chemotherapy treatment $(p<0.05)$.

In multivariate analysis, patients with RON and MET coexpression had much higher relative risk (RR: 1.664; 95\%
CI, 1.169-2.369; $p<0.01)$ than patients with RON or MET negative expression. Patients with RON expression had much higher RR (RR: 1.911; 95\% CI, 1.271-2.875; $p<0.01$ ) than the RON-negative control. The same result was obtained for MET expression (RR: 1.967; 95\% CI, 1.193-3.244; $p<0.01$ ). In addition, distant metastasis $(p<0.01)$, age $(p<0.05)$, tumor size $(p<0.01)$, and chemotherapy $(p<0.01)$ remained independent prognostic factors of poor OS (Table S1).

\section{Effect of TKIs in vitro on Pancreatic Cancer Cell Viability, Migration, and Apoptosis}

In BxPC3 cells, TKI treatment reduced cell viability significantly in a time- and dose-dependent manner, except for INCB28060 (Figure S2). There was $>80 \%$ reduction in cell viability when BxPC3 cells were treated with $15 \mu \mathrm{M}$ BMS777607, $15 \mu \mathrm{M}$ PHA665752, or $15 \mu \mathrm{M}$ Tivantinib at $72 \mathrm{~h}$, and only $<20 \%$ reduction in cell viability when the cells were treated 
with $15 \mu \mathrm{M}$ INCB28060. The calculated IC50 values of BMS777607, PHA665752, and Tivantinib at $72 \mathrm{~h}$ were 1.96 , 3.18 , and $0.31 \mu \mathrm{M}$, respectively. Although the IC50 value in BxPC3 cell viability differed, increasing the concentration of BMS777607 and PHA665752 had the same inhibitory effect as Tivantinib (Figure 2A). The TKIs had the same effect on AsPC1 cell viability as that on BxPC3 cells, and the calculated IC50 values of BMS777607, PHA665752, and Tivantinib at $72 \mathrm{~h}$ were $3.87,4.22$, and $0.60 \mu \mathrm{M}$, respectively (Figure S2). In L3.6p1 cells, the calculated IC50 values of BMS777607, PHA665752, and Tivantinib at $72 \mathrm{~h}$ were $5.13,4.24$, and $0.63 \mu \mathrm{M}$, respectively. In Panc1

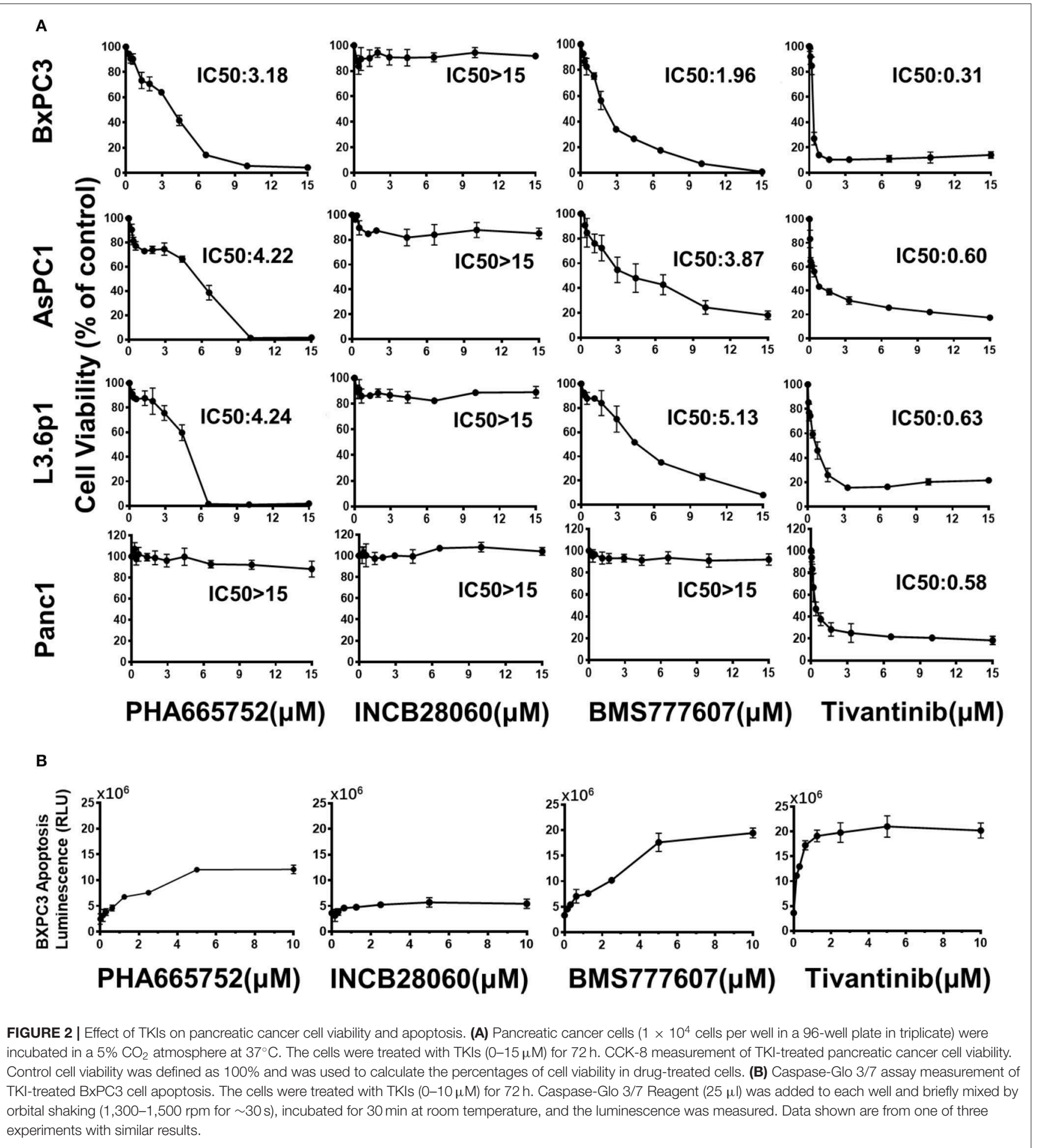




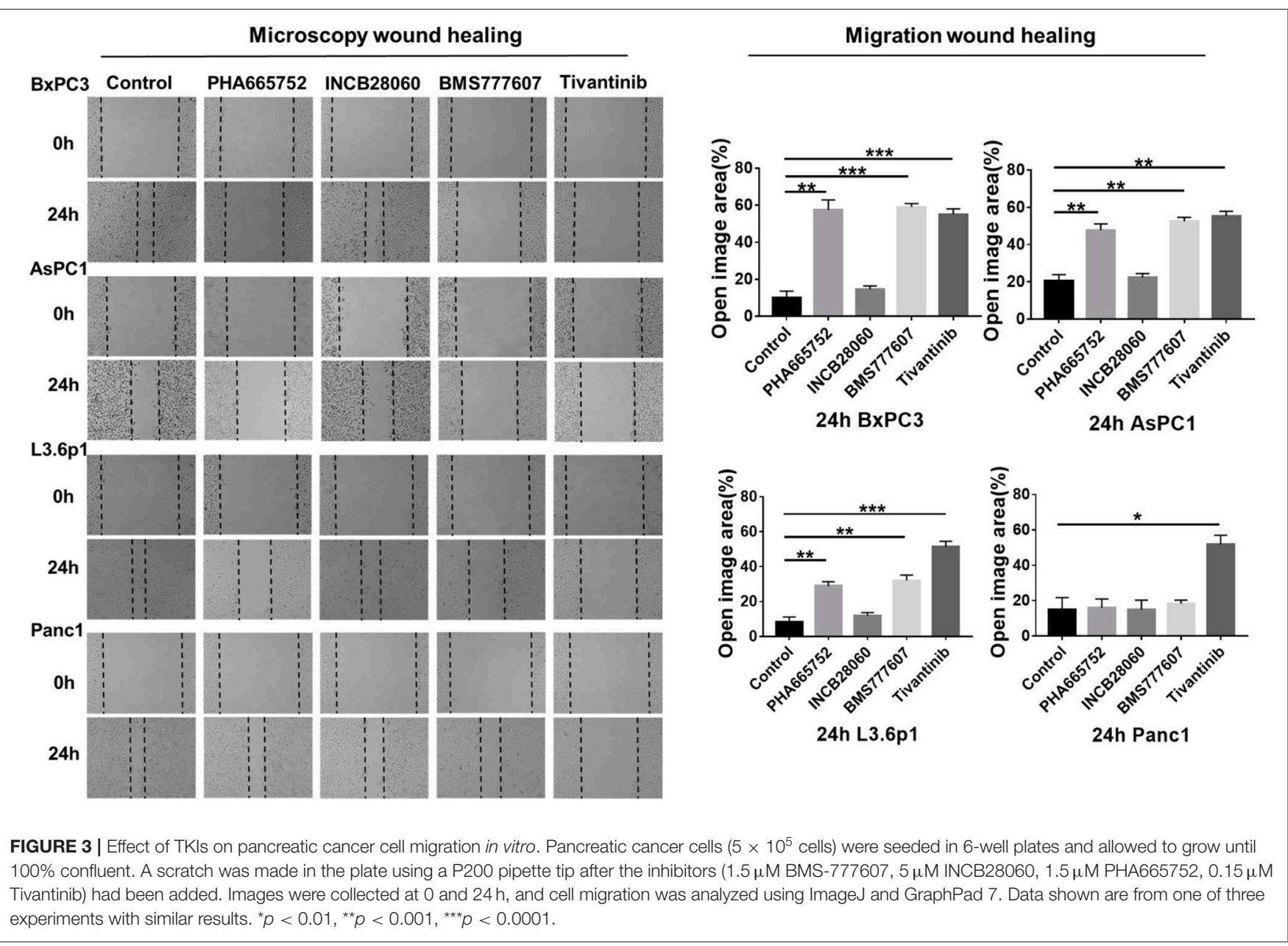

cells, only Tivantinib affected cell viability (IC50 of $0.58 \mu \mathrm{M}$ ) (Figure 2A).

The Caspase-Glo $3 / 7$ assays showed that Tivantinib, BMS777607, and PHA665752 promoted BxPC3 cell apoptosis in dose-dependently. In contrast, INCB28060 had low effects on BxPC3 cell apoptosis (Figure 2B).

Enhanced cell motility and invasiveness are important features of tumor progression. Therefore, we used the wound healing assay to investigate the effect of the TKIs on cell migration and invasion. After $24 \mathrm{~h}$, wound healing was significantly reduced ( $n=3$, 2-tailed unpaired $t$-test, $p<0.001$ ) in BxPC3 cells treated with $1.5 \mu \mathrm{M}$ PHA665752, $1.5 \mu \mathrm{M}$ BMS777607, and $0.15 \mu \mathrm{M}$ tivantinib, with $57.49,59.12$, and $55.07 \%$ open area, respectively, compared to the scrambled control vector set with $10.07 \%$ open area. AsPC1 cells yielded similar results to that of the $\mathrm{BxPC} 3$ cells. Wound healing was also reduced $(p<0.001)$ in L3.6p1 cells treated with $1.5 \mu \mathrm{M}$ PHA665752 and $1.5 \mu \mathrm{M}$ BMS777607, with 28.98 and $32.07 \%$ open area, respectively, compared to the $8.26 \%$ of the empty vector. In Pancl cells, only Tivantinib reduced cell migration significantly compared to scrambled control at $24 \mathrm{~h}(p<0.01)$. Compared with the other three inhibitors, INCB28060 had no inhibitory effect on pancreatic cancer cell migration after $24 \mathrm{~h}$ (Figure 3).

From the above results, we concluded that BMS777607 and PHA665752, both targeting RON and MET, can significantly inhibit pancreatic cancer cell viability and migration and promote apoptosis. At the same time, INCB28060, targeting MET, had almost no effect on pancreatic cancer cell viability, migration, and apoptosis. Tivantinib exhibited a good inhibitory effect on pancreatic cancer cells independently of MET inhibition.

\section{Effect of TKIs on Cellular Signaling}

The requirement of RON and MET for downstream signaling activation and cellular functions was studied using smallmolecule TKIs in BxPC3 cells. BxPC3 cells were treated with $2 \mathrm{nM}$ MSP and $2 \mathrm{nM} \mathrm{HGF}$, followed by TKIs $(5 \mu \mathrm{M}$ BMS-777607, $5 \mu \mathrm{M}$ INCB28060, $5 \mu \mathrm{M}$ PHA665752, $0.5 \mu \mathrm{M}$ Tivantinib) for $60 \mathrm{~min}$ at $37^{\circ} \mathrm{C}$, and then phospho-RON and phospho-MET expression were analyzed by western blotting. MSP and HGF significantly stimulated RON and MET phosphorylation as compared to the control. BMS777607 and PHA665752 significantly silenced phospho-RON and 


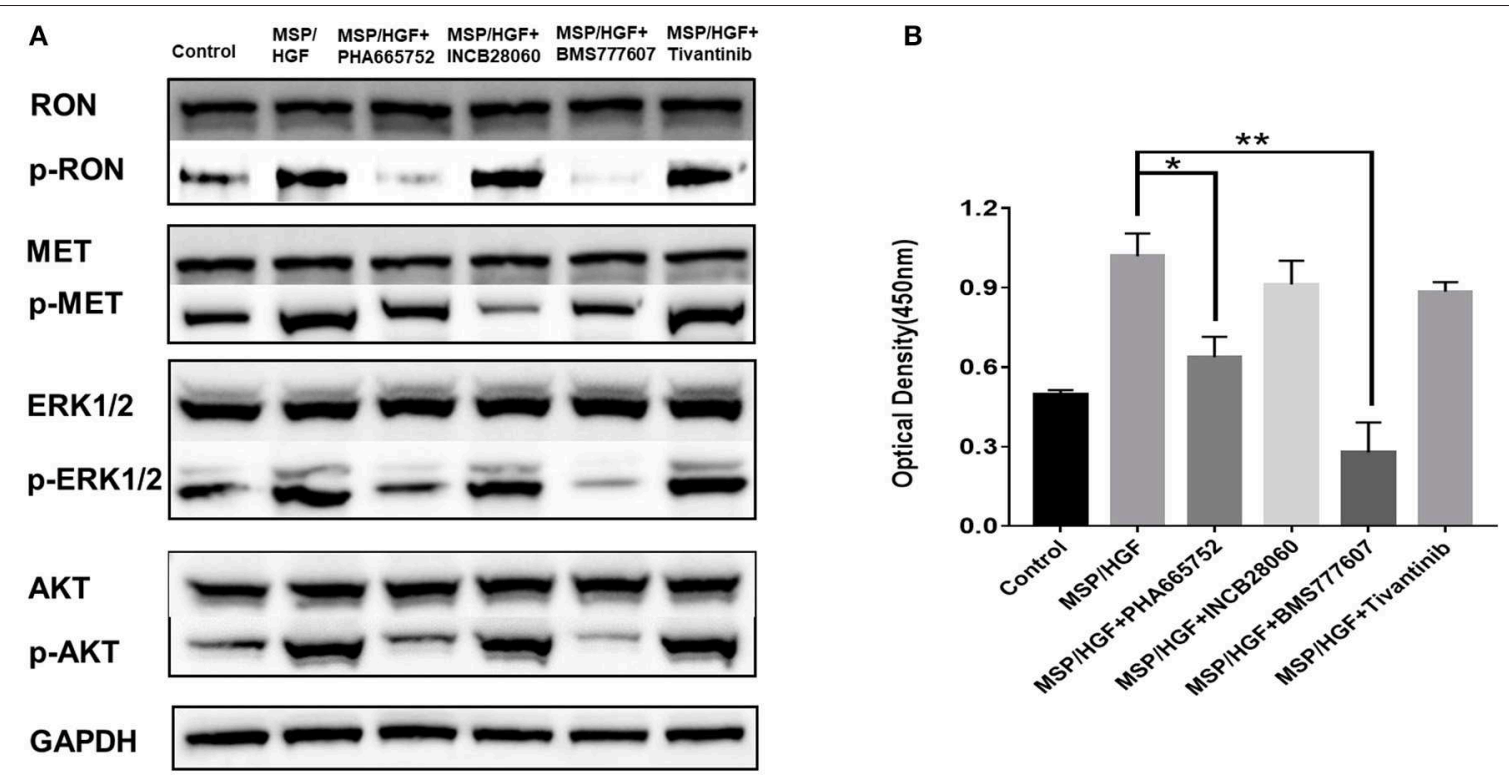

FIGURE 4 | Effect of TKIs on cellular signaling. (A) Western blot of BxPC3 cells treated MSP, HGF, and TKIs $(5 \mu \mathrm{M}$ BMS777607, $5 \mu \mathrm{M}$ INCB28060, $5 \mu \mathrm{M}$ PHA665752, $0.5 \mu \mathrm{M}$ Tivantinib). Proteins analyzed include RON, MET, AKT, ERK1/2, phospho-AKT, and phospho-ERK1/2. The membranes were also reprobed for GAPDH as the loading control. Phosphorylated RON and MET were analyzed by western blotting after immunoprecipitation. (B) ELISA measurement of phosphorylated human RON in BxPC3 cells as above. * $p<0.01,{ }^{* *} p<0.001$.

phospho-MET expression. Moreover, inhibiting phospho-RON and phospho-MET expression significantly diminished both AKT and ERK1/2 phosphorylation, but had no effect on their protein expression. INCB28060 only inhibited phosphoMET expression, and had no effect on the downstream signaling pathway. Therefore, RON and MET signaling is critical in AKT and ERK1/2 activation, and BMS-777607 and PHA665752 might inhibit RON- and MET-mediated tumorigenesis (Figure 4A).

The same cell lysates treated with MSP, HGF, and inhibitors were also analyzed by ELISA to measure phospho-RON expression. The BMS777607 and PHA665752 group had significantly diminished optical density values $(P<0.01)$ compared to the MSP-alone group. These results corroborated BMS777607 and PHA665752 significantly decreasing phosphoRON and phospho-MET expression (Figure 4B).

\section{Therapeutic Effect of TKIs in vivo Inhibition of Xenograft Pancreatic Cancer Growth}

Inoculating pancreatic cancer cells $\left(5 \times 10^{6}\right.$ cells per mouse $)$ into the mammary fat pad caused tumor growth in a timedependent manner. The pancreatic cancer cells were oncogenic in the nude mice and rapidly caused tumor formation and growth in vivo. Treatment of the mice bearing pancreatic cancer xenografts $\left(\sim 100 \mathrm{~mm}^{3}\right)$ was initiated with repeated injection of $20 \mathrm{mg} / \mathrm{kg} /$ day Tivantinib, $5 \mathrm{mg} / \mathrm{kg} /$ day INCB28060, $25 \mathrm{mg} / \mathrm{kg} /$ day BMS777607, or $25 \mathrm{mg} / \mathrm{kg} /$ day PHA665752, with a total of 14 doses for 14 days. In BxPC3 xenografts, Tivantinib, PHA665752, and BMS777607 inhibited BxPC3 cell-mediated tumor growth in a time-dependent manner. Significantly reduced $(p<0.0001)$ tumor volume was observed after Tivantinib,
BMS777607 and PHA665752 treatment at day 20. At day 27, the mice in the control and INCB28060 groups were euthanized when tumor volumes exceeded $2,000 \mathrm{~mm}^{3}$. Compared to the control group, the PHA665752-, BMS777607-, and Tivantinibtreated mice had 52.32, 70.36, and $64.0 \%$ reduced tumor growth, respectively (Figure 6A). Then, at day 37, 43, and 47, mice in the PHA665752, Tivantinib, and BMS777607 groups were euthanized when tumor volumes exceeded 2,000 $\mathrm{mm}^{3}$. Compared with the control, BMS777607, Tivantinib, and PHA665752 extended the life of the mice by 20, 16, and 10 days, respectively (Figure 6A).

Due to the slower tumor growth speed of the AsPC1 xenograft tumor model as compared to the BxPC3 xenograft tumor model, we started the treatment at day 9. At day 60, all mice were euthanized. The tumor size and mouse body weight of the control and INCB28060 groups were not significantly different (Figure 5). The tumor weights of the PHA665752-treated mice $(0.22 \pm 0.14 \mathrm{~g})$ and BMS777607-treated mice $(0.06 \pm 0.03 \mathrm{~g})$ were much lower than that of the control group (0.86 \pm $0.19 \mathrm{~g}, p<0.01$ ) (Figure 5C). Compared to the control group, the PHA665752- and BMS777607-treated mice had 74.42 and 93.02\% tumor weight reduction, respectively. There were hardly any tumors in the BMS777607 group (Figure 5B). And the tumor volume of the PHA665752- and BMS777607-treated mice were much lower than that of the control group.

In L3.6p1 xenografts, BMS777607, and Tivantinib had a significant inhibitory effect on tumor growth, and average inhibition in tumor weight with statistical difference $(p<$ 0.01 ) was 35.67 and $54.97 \%$ in the BMS777607 and Tivantinib groups, respectively (Figures 5A,C). In Panc1 xenografts, only Tivantinib had an obvious inhibitory effect as compared 


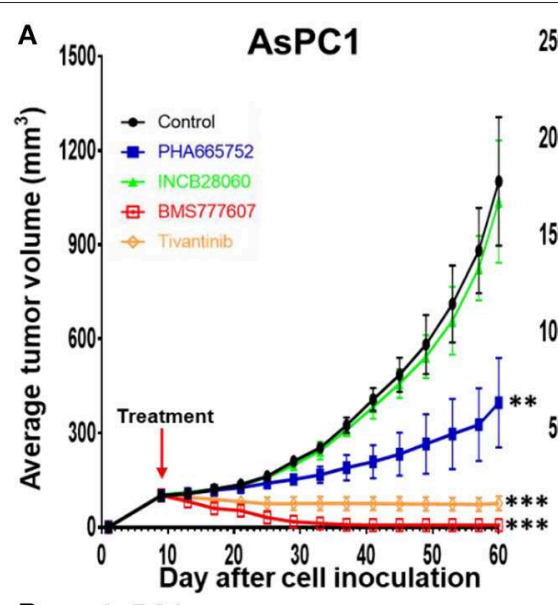

B
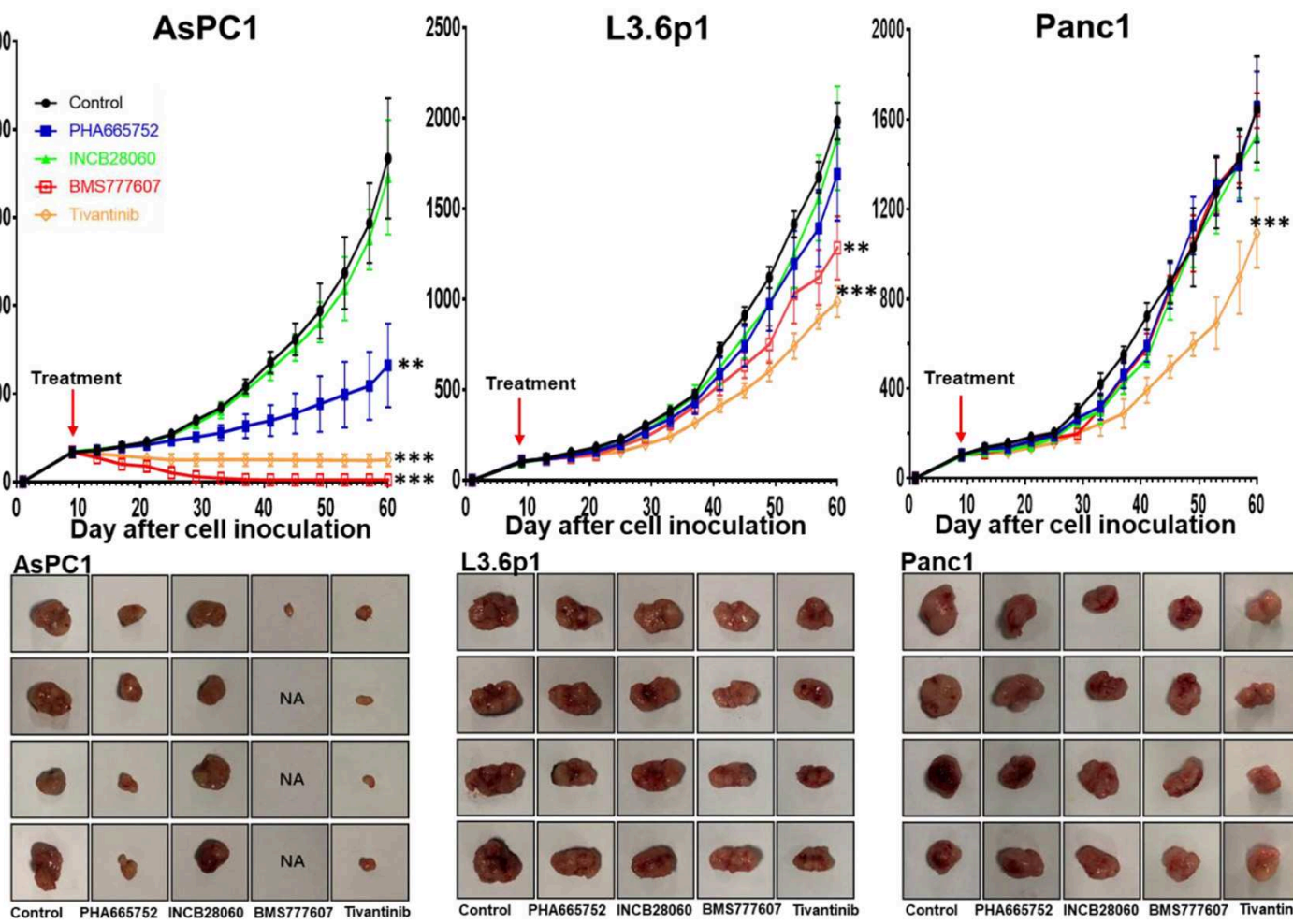

L3.6p1

C
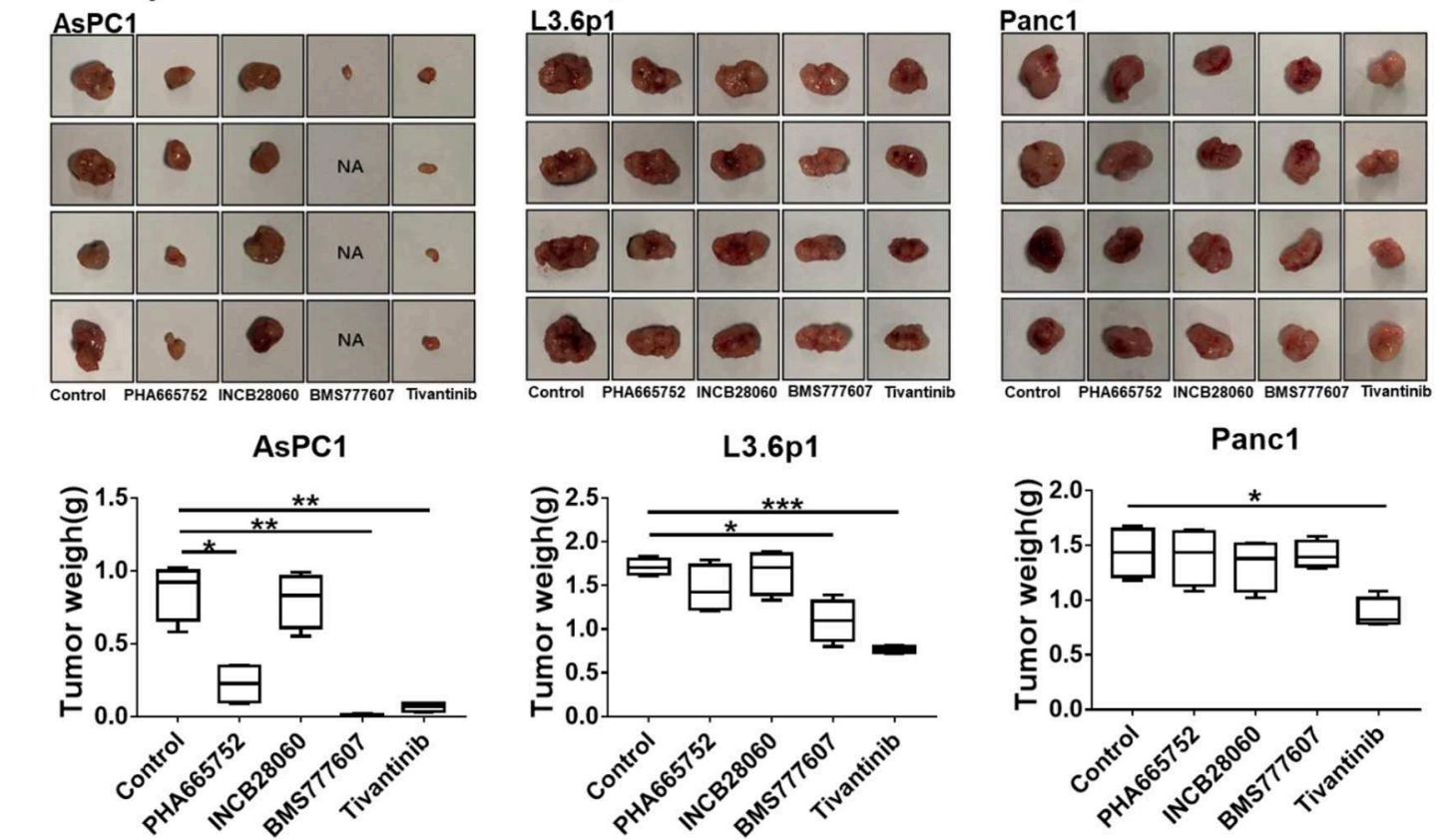

Panc1

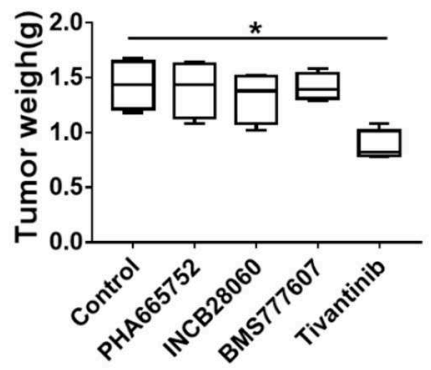

FIGURE 5 | Therapeutic efficacy of TKIs in pancreatic cancer xenograft tumor models in vivo. (A) Average tumor volumes from nude mice ( $n=4$ per group) inoculated with $5 \times 10^{6}$ AsPC1, L3.6p1, or Panc1 cells. (B) Individual tumors from each treatment group. NA, no tumors were observed in the injected site. (C) Tumor weights of nude mice ( $n=4$ per group) inoculated with AsPC1, L3.6p1, or Panc1 cells. ${ }^{*} p<0.01,{ }^{* *} p<0.001,{ }^{* * *} p<0.0001$.

to the control, and the Tivantinib group had much lower average tumor weight $(0.88 \pm 0.13 \mathrm{~g})$ than the control group $(1.43 \pm 0.22 \mathrm{~g}, p<0.01$ ) (Figure 5C). During the TKI treatment, all three groups of mice remained healthy and gained weight.

Analysis of the lysate proteins from BxPC3 cell xenograft tumors confirmed that phospho-RON and phospho-MET expression was significantly diminished in the BMS777607treated groups. The PHA665752-treated groups had significantly diminished phospho-RON expression and slightly diminished phospho-MET expression. Moreover, inhibiting phosphoRON and phospho-MET expression significantly diminished both AKT and ERK1/2 phosphorylation, but had no effect on their protein expression. In the INCB28060treated groups, inhibiting only phospho-MET expression had no effect on the downstream signaling pathway (Figure 6B).

\section{DISCUSSION}

Pancreatic cancer is a digestive system malignancy of global health concern. Angiogenesis, the presence of highly resistant cancer stem cells, and dysregulation of the cell cycle and apoptosis are thought to be critical in pancreatic cancer chemoresistance (39). Due to the highly proliferative and chemoresistant nature of pancreatic cancer, current therapeutic options such as chemoradiotherapy can do little to improve survival and patient quality of life. At the same time, most patients with pancreatic cancer are diagnosed late and often miss the opportunity for surgery. The development of precision 

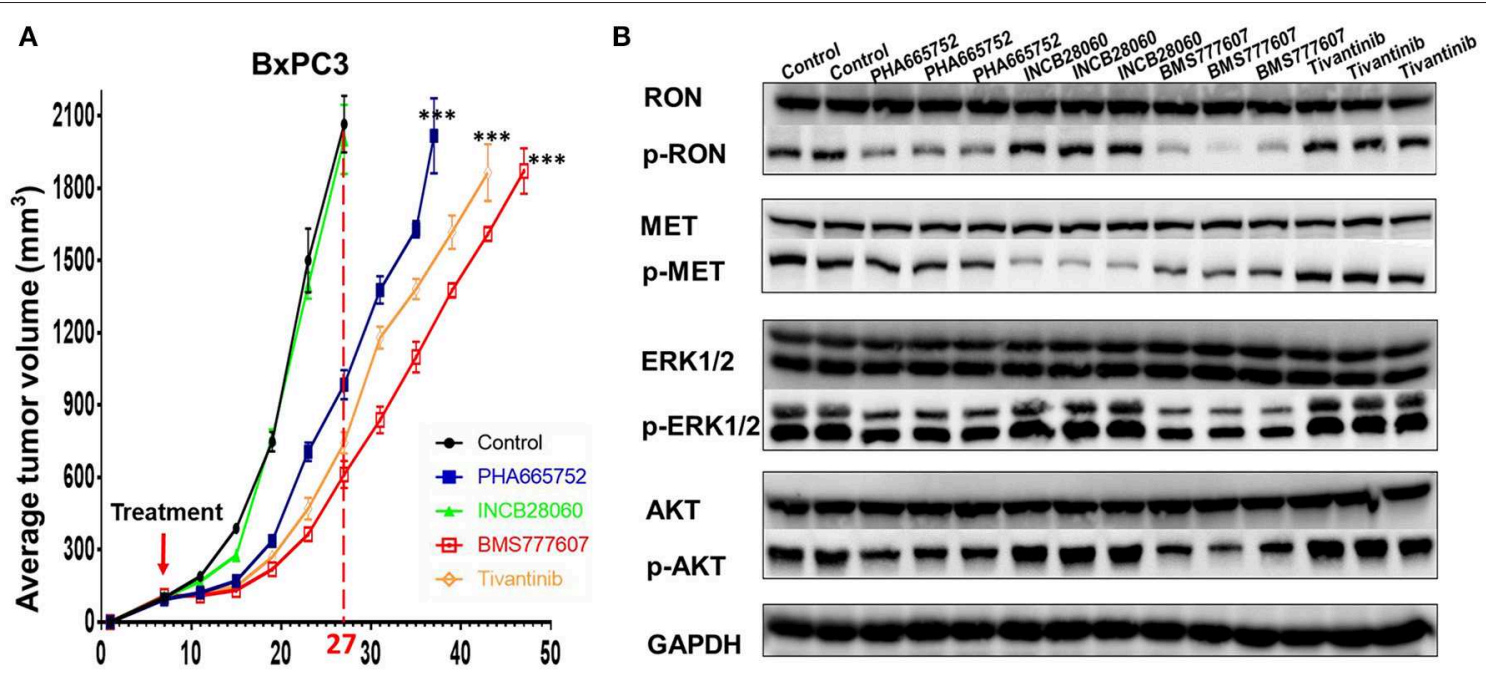

FIGURE 6 | Effect of TKIs on RON, MET expression, cellular signaling and tumor growth in BxPC3 xenograft tumor models. (A) Average tumor volumes from nude mice ( $n=4$ per group) inoculated with $5 \times 10^{6}$ BxPC3 cells. ${ }^{* \star *} p<0.0001$. (B) A portion of BxPC3 tumor samples from different groups were lysed using tissue lysis buffer as previously described. Proteins (50 $\mathrm{g}$ per sample) were analyzed by western blotting to detect RON, MET, AKT, ERK1/2, phospho-AKT, and phospho-ERK1/2. Phospho-RON and phospho-MET were analyzed by western blotting after immunoprecipitation.

medicine, which can support the personalized therapeutic approach, is likely a future treatment hope for pancreatic cancer. Better understanding of the signaling pathways and mechanisms dysregulated during pancreatic cancer development aid the development of targeted treatment of pancreatic cancer (40).

Studies from the past decade have shown that RON and MET play a role in most known cancer subtypes and are potential markers of poor prognosis and therapeutic target in a number of cancers $(41,42)$. In the present study, we found increased RON and MET expression in pancreatic cancer tissues, and RON and MET expression were highly correlated. RON and MET were important independent risk factors. As RON and MET expression levels increased, survival became shorter; survival was obviously shorter in RON and MET cooverexpression. Accordingly, RON and MET can be important diagnosis biomarkers and prognosis indicators in pancreatic cancer. However, some studies have shown that RON expression is not associated with prognosis in resected pancreatic cancer (43). There are also some studies showed that elevated MET expression is a strong and independent risk factors of poor patient survival compared to RON, and the MET and RON coexpression does not appear to reflect a synergistic mechanism of reducing pancreatic cancer patient survival times (19). This may be due to the differences in RON expression at RNA and protein level. Moreover, there are many variants of RON, and different antibodies recognize different variants of RON. In addition, IHC staining showed that elevated RON expression in the pancreatic cancer tissue samples was associated with distant metastasis, but that MET expression was associated with tumor size in our study. In a recent study by Babicky $\mathrm{ML}$ et al., they found that RON expression can accelerate pancreatic carcinogenesis and loss of functional RON slows progression to pancreatic cancer. They also found RON knockdown significantly inhibits tumor growth in vivo (20). In the future, we suggest that the combined detection of RON and MET in tumor tissue has better clinical value for the pathological diagnosis and prognosis evaluation in patients with pancreatic cancer. We assume that RON and MET are suitable targets in pancreatic cancer treatment, and new therapy will further increase survival.

We used four small-molecule TKIs (BMS777607, PHA665752, INCB28060, Tivantinib) to explore the function of RON and MET in pancreatic cancer cells and whether RON and MET could serve as new targets for future treatment of pancreatic cancer. BMS777607 and PHA665752, both targeting RON and MET, could inhibit pancreatic cancer cell viability and migration and induce apoptosis effectively (Figures 2, 3). They also inhibited tumor growth in the pancreatic cancer xenograft tumor model (Figure 5). INCB28060, targeting MET alone, had almost no effect on the cell viability, migration, and tumor growth of the four pancreatic cancer cell lines and the xenograft tumor model. Tivantinib is the first drug to be tested in phase III clinical trials (NCT01755767, METIV-HCC; NCT02029157, JET-HCC) (29). It can affect microtubule dynamics independently of MET, induce G2/M arrest, and induce apoptosis (29). In the present research, we confirm that Tivantinib cannot inhibit the MET and downstream signaling pathways, but that it has a good inhibitory effect on pancreatic cancer cells. In vivo and in vitro assays all confirmed that TKIs targeting RON had better inhibitory effects and that inhibiting MET alone had almost no effect. These data indicate that survival is obviously shorter in patients with pancreatic cancer with RON and MET co-overexpression, and that TKIs targeting RON and MET, e.g., BMS777607, might be of great significance for treating pancreatic cancer, especially in patients with high RON and MET expression, and for prolonging survival. However, TKIs targeting MET alone had almost no inhibitory effect. RON is more meaningful as a 
new target of future pancreatic cancer treatment. This may be because RON can mediate oncogenic phenotypes and addiction to KRAS signaling (20). Some researchers have found that "KRAS addiction" is associated with EMT (epithelial to mesenchymal transition) and tumor cell survival (44). Furthermore, RONmediated EMT is mainly achieved by activating both the RASERK and PI3K-AKT signaling pathways (7). Most of the pancreatic cancer cell lines have KRAS mutations. Therefore, RON, an important KRAS effector, may play a very important role in pancreatic cancer (45). Here, the lack of inhibitory effect by the MET-targeting TKIs was probably related to dosage, drug resistance, and pancreatic cancer cells being highly dependent RON signaling. This report validates the preclinical efficacy of anti-RON and MET for potential targeted therapy of pancreatic cancer.

In addition, many molecular targets have been developed in pancreatic cancer. Erlotinib and gefitinib, TKIs in phase III studies, block EGFR (epidermal growth factor receptor) selectively. Trastuzumab and cetuximab are mAbs against the HER2/neu (erb-b2 receptor tyrosine kinase 2) receptor and EGFR, respectively (46). Moreover, as many targeted agents have been developed, we confirmed that Zt/g4-DM1, as a model of RON-targeted drug delivery for treating pancreatic cancer, is highly effective alone or in combination with chemotherapeutics for inhibiting pancreatic cancer xenograft growth (22).

RON and MET belong to a family of tyrosine kinase receptors and have similar structures. Many researchers have investigated the possible cross-talk between $\operatorname{RON}$ and $\operatorname{MET}(16,19,47)$. There is transphosphorylation between RON and MET and reciprocal regulation of the kinase activity. Homo- and heterodimers of RON and MET are present on the cell surface. Therefore, the formation of a RON and MET complex leads to more efficient RON transphosphorylation by MET, and therefore activates the downstream signaling pathways more effectively (16). There is research revealed BxPC3 cells co-express the RON and MET expression at the cell population level and HGF and MSP can both activate ERK1/2 in BxPC3 cells (19). This is very consistent with our findings. Flow cytometric and western blot analysis showed that the BxPC3 cells had RON and MET co-expression in our study. Here, we also found that RON and MET can be activated by their ligands MSP and HGF, respectively, and further activate the downstream signaling pathways in BxPC3 cells. Next, we found that BMS777607 and PHA665752 inhibition of RON and MET phosphorylation can better inhibit the downstream signaling pathways and that INCB28060 inhibiting MET alone does not inhibit the downstream signaling pathways effectively (Figure 4). These findings confirm the cross-talk between RON and MET. The data also demonstrate that the MSP-RON signaling pathway, but not the HGF-MET signaling pathway, may be the dominant mechanism for cell viability and metastasis.

Moreover, the positive correlation of RON expression with MET has been reported in prostate cancer, and patients with RON and MET co-expression had the lowest 10-years disease-free survival in node-negative breast cancer $(48,49)$. Others have found that knockdown of MSP-RON signaling delays tumor progression and enhances HGF-MET signaling in pancreatic cancer cell lines (47). HGF-MET and MSP-RON can increase cell migration, but only HGF-MET increases proliferation in BxPC3 cells (19). HGF-MET signaling may play an important role in the invasion and metastasis of pancreatic cancer cells (47). And HGF-MET may be the dominant mechanism mediating EMT in prostate cancer cell lines (48). MET activation can also serve as a primary oncogenic driver or a secondary driver of acquired resistance to targeted therapy in different subsets of lung cancer (42). However, other research has suggested that RON plays a prominent role in both cancer cells and the tumor-associated microenvironment (7). This may be closely related with tumor heterogeneity and complexity. Moreover, RON overexpression can increase gemcitabine resistance in pancreatic cancer, and RON inhibition sensitizes pancreatic ductal adenocarcinoma (PDAC) cells to gemcitabine (20). Many patients with pancreatic cancer with gemcitabine-resistance might benefit from a combination of RON and/or MET inhibitors.

In the present study, we compared the inhibitory effects of four TKIs on human pancreatic cancer cell lines expressing variable levels of RON and MET. We demonstrate clearly that RON and MET can be new therapeutic targets in pancreatic cancer. RON is more meaningful as a new future therapeutic target than MET. However, RON and MET may interact with many other RTKs. In human cancer, the RTKs RON, MET, and EGFR are frequently co-expressed and promote resistance to targeted therapeutics (50). TKIs targeting only RON and MET may not be sufficiently effective. Accordingly, combining the RON-targeting inhibitors with chemotherapy or other targeted agents may achieve a better treatment effect. The present findings uncover the synergism effect between TKIs and gemcitabine via in vitro and in vivo experiments. In the future, we will evaluate the potential use of these TKIs targeting RON and MET in combination with gemcitabine. Moreover, further understanding of the cross-talk of these receptors may present more possibilities for treating pancreatic cancer.

In conclusion, RON and MET are widely expressed in pancreatic cancer tissues. RON and MET expression are highly correlated with OS in pancreatic cancer. RON and MET may be involved in the malignant process of pancreatic cancer, and can serve as a biomarker for evaluating the prognosis of patients with pancreatic cancer. There is a complex cross-talk between RON and MET. We believe that the MSP-RON signaling pathway, but not the HGF-MET signaling pathway, may be the dominant mechanism in pancreatic cancer. TKIs targeting RON and MET have a better inhibitory effect on pancreatic cancer cell in vivo and vitro experiment. Increased RON and MET expression by pancreatic cancer cells is a suitable target for anti-RON and antiMET drugs in future cancer therapy. These findings also provide support for the use of TKIs targeting RON and RON/MET as a novel and potential approach for pancreatic cancer therapy.

\section{DATA AVAILABILITY STATEMENT}

The raw data supporting the conclusions of this manuscript will be made available by the authors, without undue reservation, to any qualified researcher. 


\section{ETHICS STATEMENT}

The Ethics Committee of The First Affiliated Hospital, Zhejiang University School of Medicine, approved the present study (reference numbers: 2017427-1 and 2017400-1).

\section{CONSENT FOR PUBLICATION}

We have obtained consent to publish this paper from all the participants.

\section{AUTHOR CONTRIBUTIONS}

Study conceptualization and supervision was carried out by H-PY, X-MX, and M-HW. Sample collection, resources, IHC, and/or clinical characterization were conducted by $\mathrm{H}-\mathrm{PY}, \mathrm{C}-\mathrm{YH}$, $\mathrm{X}-\mathrm{MX}, \mathrm{BH}, \mathrm{Z}-\mathrm{GW}, \mathrm{YQ}$, and T-HW. The in vitro cellular experiments and data analysis were performed by C-YH, T-HW, T-MT, and Y-ZL. The animal experiments were carried out by

\section{REFERENCES}

1. Stathis A, Moore MJ. Advanced pancreatic carcinoma: current treatment and future challenges. Nat Rev Clin Oncol. (2010) 7:163-72. doi: 10.1038/nrclinonc.2009.236

2. Vincent A, Herman J, Schulick R, Hruban RH, Goggins M. Pancreatic cancer. Lancet. (2011) 378:607-20. doi: 10.1016/S0140-6736(10)62307-0

3. Rahib L, Smith BD, Aizenberg R, Rosenzweig AB, Fleshman JM, Matrisian LM. Projecting cancer incidence and deaths to 2030: the unexpected burden of thyroid, liver, and pancreas cancers in the United States. Cancer Res. (2014) 74:2913-21. doi: 10.1158/0008-5472.CAN-14-0155

4. Ronsin C, Muscatelli F, Mattei MG, Breathnach R. A novel putative receptor protein tyrosine kinase of the met family. Oncogene. (1993) 8:1195-202.

5. Park M, Dean M, Kaul K, Braun MJ, Gonda MA, Woude GF. Sequence of MET protooncogene cDNA has features characteristic of the tyrosine kinase family of growth-factor receptors. Proc Natl Acad Sci USA. (1987) 84:6379-83. doi: 10.1073/pnas.84.18.6379

6. Cooper CS, Park M, Blair DG, Tainsky MA, Huebner K, Croce CM, et al. Molecular cloning of a new transforming gene from a chemically transformed human cell line. Nature. (1984) 311:29-33. doi: 10.1038/311029a0

7. Yao HP, Zhou YQ, Zhang RW, Wang MH. MSP-RON signalling in cancer: pathogenesis and therapeutic potential. Nat Rev Cancer. (2013) 13:46681. doi: $10.1038 / \mathrm{nrc} 3545$

8. Vigna E, Naldini L, Tamagnone L, Longati P, Bardelli A, Maina F, et al. Hepatocyte growth factor and its receptor, the tyrosine kinase encoded by the c-MET proto-oncogene. Cell Mol Biol. (1994) 40:597-604.

9. Hanna JA, Bordeaux J, Rimm DL, Agarwal S. Chapter 1 the function, proteolytic processing, and histopathology of met in cancer. Adv Cancer Res. (2009) 103:1-23. doi: 10.1016/S0065-230X(09)03001-2

10. Birchmeier C, Birchmeier W, Gherardi E, Vande Woude GF. Met, metastasis, motility and more. Nat Rev Mol Cell Biol. (2003) 4:91525. doi: 10.1038/nrm1261

11. Muraoka RS, Sun WY, Colbert MC, Waltz SE, Witte DP, Degen JL, et al. The Ron/STK receptor tyrosine kinase is essential for periimplantation development in the mouse. J Clin Invest. (1999) 103:127785. doi: 10.1172/JCI6091

12. Uehara Y, Minowa O, Mori C, Shiota K, Kuno J, Noda T, et al. Placental defect and embryonic lethality in mice lacking hepatocyte growth factor/scatter factor. Nature. (1995) 373:702-05. doi: 10.1038/373702a0

13. McClaine RJ, Marshal AM, Wagh PK, Waltz SE. Ron receptor tyrosine kinase activation confers resistance to tamoxifen in breast cancer cell lines. Neoplasia. (2010) 12:650-58. doi: 10.1593/neo.10476
C-YH, T-MT, and Y-ZL. The manuscript was drafted by H-PY, M$\mathrm{HW}$, and C-YH. All authors read and approved the manuscript.

\section{FUNDING}

This work was supported by National Natural Science Foundation of China grant \#81872883 (to H-PY), Zhejiang Major Medical Health \& Sciences Technology Foundation Projects \#WKJ-ZJ-13 and \#2014C33204 (to H-PY), and Zhejiang Provincial Natural Science Foundation of China grant \#LY18H160014 (to X-MX). The funders had no role in the study design, data collection and analysis, decision to publish, or preparation of the manuscript.

\section{SUPPLEMENTARY MATERIAL}

The Supplementary Material for this article can be found online at: https://www.frontiersin.org/articles/10.3389/fonc. 2019.01377/full\#supplementary-material

14. Takeuchi H, Bilchik AJ, Saha S, Turner RR, Wiese D, Tanaka M, et al. c-MET expression level in primary colon cancer a predictor of tumor invasion and lymph node metastases. Clin Cancer Res. (2003) 9:1480-88.

15. Zhao S, Ammanamanchi S, Brattain M, Cao L, Thangasamy A, Wang J, et al. Smad4-dependent TGF- $\beta$ signaling suppresses RON receptor tyrosine kinasedependent motility and invasion of pancreatic cancer cells. J Biol Chem. (2008) 283:11293-301. doi: 10.1074/jbc.M800154200

16. Follenzi A, Bakovic S, Gual P, Stella MC, Longati P, Comoglio PM. Crosstalk between the proto-oncogenes Met and Ron. Oncogene. (2000) 19:304149. doi: 10.1038/sj.onc. 1203620

17. Camp ER, Yang AD, Gray MJ, Fan F, Hamilton SR, Evans DB, et al. Tyrosine kinase receptor RON in human pancreatic cancer: expression, function, and validation as a target. Cancer. (2007) 109:1030-39. doi: 10.1002/cncr.22490

18. Modica C, Tortarolo D, Comoglio PM, Basilico C, Vigna E. MET/HGF Cotargeting in pancreatic cancer: a tool to provide insight into the tumor/stroma crosstalk. Int J Mol Sci. (2018) 19:3920. doi: 10.3390/ijms19123920

19. Vanderwerff BR, Church KJ, Kawas LH, Harding JW. Comparative characterization of the HGF/Met and MSP/Ron systems in primary pancreatic adenocarcinoma. Cytokine. (2019) 123:11. doi: 10.1016/j.cyto.2019.154762

20. Babicky ML, Harper MM, Chakedis J, Cazes A, Mose ES, Jaquish DV, et al. MST1R kinase accelerates pancreatic cancer progression via effects on both epithelial cells and macrophages. Oncogene. (2019) 38:5599611. doi: 10.1038/s41388-019-0811-9

21. Yao HP, Feng L, Suthe SR, Chen LH, Weng TH, Hu CY, et al. Therapeutic efficacy, pharmacokinetic profiles, and toxicological activities of humanized antibody-drug conjugate Zt/g4-MMAE targeting RON receptor tyrosine kinase for cancer therapy. I Immunother Cancer. (2019) 7:1. doi: 10.1186/s40425-019-0525-0

22. Yao HP, Feng L, Zhou JW, Zhang RW, Wang MH. Therapeutic evaluation of monoclonal antibody-maytansinoid conjugate as a model of RON-targeted drug delivery for pancreatic cancer treatment. Am J Cancer Res. (2016) 6:937-56.

23. Sharma S, Zeng JY, Zhuang CM, Zhou YQ, Yao HP, Hu X, et al. Smallmolecule inhibitor BMS-777607 induces breast cancer cell polyploidy with increased resistance to cytotoxic chemotherapy agents. Mol Cancer Ther. (2013) 12:725-36. doi: 10.1158/1535-7163.MCT-12-1079

24. Takiguchi S, Inoue K, Matsusue K, Furukawa M, Teramoto N, Iguchi H. Crizotinib, a MET inhibitor, prevents peritoneal dissemination in pancreatic cancer. Int J Oncol. (2017) 51:184-92. doi: 10.3892/ijo.2017.3992

25. Yao HP, Zhuang CM, Zhou YQ, Zeng JY, Zhang RW, Wang MH. Oncogenic variant RON160 expression in breast cancer and its potential as a therapeutic 
target by small molecule tyrosine kinase inhibitor. Curr Cancer Drug Targets. (2013) 13:686-97. doi: 10.2174/15680096113139990038

26. Schroeder GM, An Y, Cai ZW, Chen XT, Clark C, Cornelius LA, et al. Discovery of N-(4-(2-Amino-3-chloropyridin-4-yloxy)-3-fluorophenyl)4-ethoxy-1-(4-flu orophenyl)-2-oxo-1,2-dihydropyridine-3-carboxamide (BMS-777607), a selective and orally efficacious inhibitor of the met kinase superfamily. J Med Chem. (2009) 52:1251-54. doi: 10.1021/jm801586s

27. Christensen JG, Schreck R, Burrows J, Kuruganti P, Chan E, Le P, et al. A selective small molecule inhibitor of c-Met kinase inhibits c-Met-dependent phenotypes in vitro and exhibits cytoreductive antitumor activity in vivo. Cancer Res. (2003) 63:7345-55.

28. Liu X, Wang Q, Yang G, Marando C, Koblish HK, Hall LM, et al. A novel kinase inhibitor, INCB28060, blocks c-MET-dependent signaling, neoplastic activities, and cross-talk with EGFR and HER-3. Clin Cancer Res. (2011) 17:7127-38. doi: 10.1158/1078-0432.CCR-11-1157

29. Rebouissou S, La Bella T, Rekik S, Imbeaud S, Calatayud AL, Rohr-Udilova $\mathrm{N}$, et al. Proliferation markers are associated with MET expression in hepatocellular carcinoma and predict tivantinib sensitivity in vitro. Clin Cancer Res. (2017) 23:4364-75. doi: 10.1158/1078-0432.CCR-16-3118

30. Munshi N, Jeay S, Li Y, Chen CR, France DS, Ashwell MA, et al. ARQ 197, a novel and selective inhibitor of the human c-met receptor tyrosine kinase with antitumor activity. Mol Cancer Ther. (2010) 9:154453. doi: 10.1158/1535-7163.MCT-09-1173

31. Reuther C, Heinzle V, Spampatti M, Vlotides G, de Toni E, Spoettl G, et al. Cabozantinib and tivantinib, but not INC280, induce antiproliferative and antimigratory effects in human neuroendocrine tumor cells in vitro: evidence for 'off-target' effects not mediated by c-met inhibition. Neuroendocrinology. (2016) 103:383-401. doi: 10.1159/000439431

32. Wang Y, Zhang H, Gigant B, Yu Y, Wu Y, Chen X, et al. Structures of a diverse set of colchicine binding site inhibitors in complex with tubulin provide a rationale for drug discovery. FEBS J. (2016) 283:10211. doi: 10.1111/febs. 13555

33. Xiang Q, Zhen Z, Deng DY, Wang J, Chen Y, Li J, et al. Tivantinib induces $\mathrm{G} 2 / \mathrm{M}$ arrest and apoptosis by disrupting tubulin polymerization in hepatocellular carcinoma. J Exp Clin Cancer Res. (2015) 34:118. doi: 10.1186/s13046-015-0238-2

34. Shah AN, Summy JM, Zhang J, Park SI, Parikh NU, Gallick GE. Development and characterization of gemcitabine-resistant pancreatic tumor cells. Ann Surg Oncol. (2007) 14:3629-37. doi: 10.1245/s10434-007-9583-5

35. Wang MH, Lee W, Luo YL, Weis MT, Yao HP. Altered expression of the RON receptor tyrosine kinase in various epithelial cancers and its contribution to tumourigenic phenotypes in thyroid cancer cells. J Pathol. (2007) 213:40211. doi: $10.1002 /$ path.2245

36. Yao HP, Feng L, Weng TH, Hu CY, Suthe SR, Mostofa AGM, et al. Preclinical efficacy of Anti-RON antibody-drug conjugate Zt/g4-MMAE for targeted therapy of pancreatic cancer overexpressing RON receptor tyrosine kinase. Mol Pharm. (2018) 15:3260-71. doi: 10.1021/acs.molpharmaceut.8b00298

37. Yao HP, Zhou YQ, Ma Q, Guin S, Padhye SS, Zhang RW, et al. The monoclonal antibody $\mathrm{Zt} / \mathrm{f} 2$ targeting $\mathrm{RON}$ receptor tyrosine kinase as potential therapeutics against tumor growth-mediated by colon cancer cells. Mol Cancer. (2011) 10:82. doi: 10.1186/1476-4598-10-82

38. Jumbe NL, Xin Y, Leipold DD, Crocker L, Dugger DL, Mai E, et al. Modeling the efficacy of trastuzumab-DM1, an antibody drug conjugate, in mice. J Pharmacokinet Pharmacodyn. (2010) 37:221-42. doi: 10.1007/s10928-010-9156-2
39. Long J, Zhang Y, Yu X, Yang J, LeBrun DG, Chen C, et al. Overcoming drug resistance in pancreatic cancer. Expert Opin Ther Targets. (2011) 15:81728. doi: $10.1517 / 14728222.2011 .566216$

40. Chandana S, Babiker HM, Mahadevan D. Therapeutic trends in pancreatic ductal adenocarcinoma (PDAC). Expert Opin Investig Drugs. (2019) 28:161-77. doi: 10.1080/13543784.2019.1 557145

41. Benight NM, Waltz SE. Ron receptor tyrosine kinase signaling as a therapeutic target. Expert Opin Ther $\begin{array}{llll}\text { Targets. (2012) 16:921-31. doi: 10.1517/14728222.2012. } & \end{array}$ 710200

42. Drilon A, Cappuzzo F, Ou SI, Camidge DR. Targeting MET in lung cancer: will expectations finally be MET? J Thorac Oncol. (2017) 12:1526. doi: $10.1016 /$ j.jtho.2016.10.014

43. Tactacan CM, Chang DK, Cowley MJ, Humphrey ES, Wu JM, Gill AJ, et al. $\mathrm{RON}$ is not a prognostic marker for resectable pancreatic cancer. BMC Cancer. (2012) 12:9. doi: 10.1186/1471-2407-12-395

44. Singh A, Greninger P, Rhodes D, Koopman L, Violette S, Bardeesy $\mathrm{N}$, et al. A gene expression signature associated with "K-Ras Addiction" reveals regulators of EMT and tumor cell survival. Cancer Cell. (2009) 15:489-500. doi: 10.1016/j.ccr.2009. 03.022

45. Logan-Collins J, Thomas RM, Yu P, Jaquish D, Mose E, French R, et al. Silencing of RON receptor signaling promotes apoptosis and gemcitabine sensitivity in pancreatic cancers. Cancer Res. (2010) 70:113040. doi: 10.1158/0008-5472.CAN-09-0761

46. Strimpakos A, Saif MW, Syrigos KN. Pancreatic cancer: from molecular pathogenesis to targeted therapy. Cancer Metastasis Rev. (2008) 27:495522. doi: 10.1007/s10555-008-9134-y

47. Zhao S, Cao L, Freeman JW. Knockdown of RON receptor kinase delays but does not prevent tumor progression while enhancing HGF/MET signaling in pancreatic cancer cell lines. Oncogenesis. (2013) 2:e76. doi: 10.1038/oncsis.2013.36

48. Yin B, Liu Z, Wang Y, Wang X, Liu W, Yu P, et al. RON and c-Met facilitate metastasis through the ERK signaling pathway in prostate cancer cells. Oncol Rep. (2017) 37:3209-18. doi: 10.3892/or.2017.5585

49. Lee WY, Chen HH, Chow NH, Su WC, Lin PW, Guo HR. Prognostic significance of co-expression of RON and MET receptors in node-negative breast cancer patients. Clin Cancer Res. (2005) 11:2222-28. doi: 10.1158/1078-0432.CCR-04-1761

50. McCleese JK, Bear MD, Kulp SK, Mazcko C, Khanna C, London CA. Met interacts with EGFR and Ron in canine osteosarcoma. Vet Comp Oncol. (2013) 11:124-39. doi: 10.1111/j.1476-5829.2011.00309.x

Conflict of Interest: The authors declare that the research was conducted in the absence of any commercial or financial relationships that could be construed as a potential conflict of interest.

Copyright (ङ $2019 \mathrm{Hu}, \mathrm{Xu}$, Hong, Wu, Qian, Weng, Liu, Tang, Wang and Yao. This is an open-access article distributed under the terms of the Creative Commons Attribution License (CC BY). The use, distribution or reproduction in other forums is permitted, provided the original author(s) and the copyright owner(s) are credited and that the original publication in this journal is cited, in accordance with accepted academic practice. No use, distribution or reproduction is permitted which does not comply with these terms. 